\title{
Animal models of pulmonary emphysema: a stereologist's perspective
}

\author{
H. Fehrenbach
}

ABSTRACT: A variety of animal models have been suggested as models of pulmonary emphysema; these are critically discussed in the present article from a stereologist's perspective. In addition, a stereological design for the quantification of experimentally induced emphysema is proposed.

On the basis of the widely accepted definition of pulmonary emphysema being an "abnormal permanent enlargement of the airspaces distal to the terminal bronchioles, accompanied by destruction of their walls," quantitative morphology is the only method with which to reliably assess the presence of emphysema. Recognising this, careful inspection of animal models that are based on instillation of elastase, genetic alterations, inhalation of cigarette smoke or induction of apoptosis, reveals that both criteria of emphysema definition were demonstrated in surprisingly few of them.

Several aspects are suggested to be critical for the understanding of animal models of human emphysema. For example, genetic models that rely on the inhibition of the formation of alveoli during post-natal alveolarisation should clearly be distinguished from models that rely on the loss of mature alveoli after alveolarisation is complete. Furthermore, inhalation models that are characterised by exposed animals exhibiting a severe loss of body weight should carefully examine the relative contribution of intervention and weight loss, respectively. Models that rely on the exposure of juvenile animals for several weeks or even months should take into account the effects of normal lung growth and ageing.

Stereology offers appropriate tools with which to quantify the parameters relevant to assess development and the regeneration of emphysema. Stereologists continue to develop tools that will help ascertain the reliability of established and new models. If inappropriate parameters continue to be used for the evaluation of animal models of emphysema, thinking and resources are likely to be misdirected and the models may limit rather than expand the understanding of human emphysema and the development of new therapies.

KEYWORDS: Animal model, chronic obstructive pulmonary disease, emphysema, quantitative morphology, stereology

hronic obstructive pulmonary disease (COPD) is predominantly a disease of the sixth decade of life and later [1]. It is characterised by irreversible airflow limitation measured during forced expiration, which is caused by either an increase in the resistance of small airways due to chronic bronchitis or an increase in lung compliance due to emphysema, or both. Several types of emphysema are distinguished in humans; for example, centriacinar emphysema, which is associated with tobacco smoking, and panacinar emphysema, which is most frequently seen in $\alpha_{1}$-antitrypsin (AT) deficiency [1, 2]. The pathogenetic pathways leading to emphysema are still a matter of debate and, even more importantly, curative therapies are still lacking [3]. For a better understanding of the underlying pathogenetic processes and the development of new therapeutic approaches, various lines of research have been followed to establish diverse animal models of emphysema. These include the development of mutant or transgenic animals, the induction of emphysema by inhalation of cigarette smoke or other noxious gases, by instillation of elastase or lipopolysaccharide or by calorie restriction, as has been comprehensively reviewed by others [4-9]. In the present article, the validity of various animal models is discussed on the basis of the quantitative morphological parameters presented to support a finding of pulmonary emphysema. In addition, a stereological design for the quantification of
CORRESPONDENCE

Dept of Internal Medicine (Respiratory Medicine) Philipps-University of Marburg Baldingerstrasse D-35043 Marburg Germany

Fax: 4964212864936

E-mail: heinz.fehrenbach@staff. uni-marburg.de

\section{SUPPORT STATEMENT}

The author gratefully acknowledges the financial support provided by the Bundesministerium für Bildung und Forschung (FKZ 01GC0103) and the Deutsche Forschungsgemeinschaft (FE287/8-1)

This paper is based on a talk given on October 9th, 2006, at the 24th Symposium of the Veterinary Comparative Respiratory Society held in Jena, Germany. 
experimentally induced emphysema is proposed that comprises a basic set of parameters necessary for the conclusive interpretation of structural changes.

\section{DEFINITION OF EMPHYSEMA AND ITS CONSEQUENCES FOR QUANTIFICATION}

Pulmonary emphysema is anatomically defined as the "abnormal permanent enlargement of the airspaces distal to the terminal bronchioles, accompanied by destruction of their walls" [10]. Both anatomical aspects can be assessed using quantitative histopathology, which revealed airspace enlargement $[11,12]$ and loss of distal lung tissue, as reflected by a significant loss of total alveolar surface area and total capillary length [13], in human lungs. Therefore, the validity of a potential animal model of emphysema has to be tested by quantitative histopathological methods measuring both airspace enlargement and destruction of the alveolar walls [14, 15]. Although an amplified inflammatory response is observed even in patients with severe emphysema [1], the mere presence of inflammatory cells characteristic of human COPD, such as neutrophilic granulocytes, activated alveolar macrophages and CD8+ T-lymphocytes, cannot be considered to be a conclusive indicator of emphysema alone.

Unfortunately, most of the experimental studies in animals presented to date rely on the quantification of airspace enlargement alone, assessing mean linear intercept (MLI) or mean linear chord (MLC) length as indices of airspace size. Although sometimes used as synonyms, it must be taken into account that MLC measures the "mean free path" within the distal airspaces [16], i.e. alveoli and alveolar ducts taken together, whereas the measurement of MLI comprises both airspace and alveolar septum [17]. Thus, a reported MLC value is always lower than the corresponding MLI value because alveolar septal wall thickness contributes to the latter. However, the use of MLI or MLC measurements to estimate alveolar size is flawed; this has previously been discussed in detail elsewhere $[15,18]$. One major critique is that MLI and MLC are inversely related to the surface/volume ratio of the airspaces and therefore crucially depend on airspace shape, as was pointed out recently by WEIBEL et al. [15]. Thus, differences between experimental groups in MLI and MLC may result either from changes in airspace size or from changes in airspace shape, or both. With regard to MLI, any change may also comprise a change in alveolar septal wall thickness. As changes in the shape of distal airspaces is a common characteristic associated with the formation of emphysema, it is impossible to discriminate between changes in airspace size or shape via the mere analysis of MLI or MLC [19]. Moreover, parameters evaluating airspace size are highly sensitive to inflation during fixation and tissue shrinkage during embedding $[20,21]$, which is widely ignored today.

As airspace size increases with age [22, 23], "abnormal" enlargement can only be demonstrated compared with agematched control lungs, and "permanent" enlargement can only be demonstrated when additional groups are implemented to demonstrate the persistence of changes in airspace size. In view of the anatomical definition, however, it is not sufficient to reveal abnormal permanent airspace enlargement alone to conclude that emphysema is present. Reliable assessment of the presence of emphysema in any animal model requires the destruction of alveolar walls to be additionally demonstrated $[14,15]$, such as a decrease in total alveolar wall volume, total alveolar surface area, total capillary length and/or total number of alveoli [18, 24, 25].

\section{ELASTASE INSTILLATION MODELS OF EMPHYSEMA}

Elastase instillation was established $>40$ yrs ago by GROss et al. [26] to develop a model of emphysema in hamsters. The establishment of this animal model had great impact on the development of the proteinase-antiproteinase concept of emphysema formation [27]. Since then, it has been adapted by many others. The attractiveness of this model is that a single hit, the instillation of a bolus of an elastolytic proteinase, such as porcine pancreatic or human neutrophil elastase, results in the loss of alveolar walls, as judged by stereology [24], whereas nonelastolytic proteinases failed to induce emphysematous lesions [28]. However, the desired effect of elastase is frequently limited to a narrow window of dosage, below which no significant loss of alveoli is observed, whereas a higher dose may result in severe pulmonary haemorrhage and high mortality [29, 30].

Notably, although MASSARO and MASSARO [31] observed an increase in the mean alveolar volume by $\sim 240 \%$, which was associated with a decrease in the total number of alveoli by $\sim 45 \%$ after elastase treatment of rat lungs using a selector approach for quantification, total alveolar surface area was insignificantly decreased by only $5 \%$. MASSARO and MASSARO [31] explained this discrepancy through the low elastic recoil of elastase-treated lungs (inferred from the increased fixed lung volume per body weight), which allowed overexpansion of the lung. Overexpansion can be expected to result in a stretchrelated decrease in the arithmetic mean thickness of the alveolar wall tissue, which should not be observed if the increase in lung volume was the result of a growth process [32]. In turn, total volume of alveolar wall tissue can be expected to increase during growth but should not be affected by overexpansion, which can be expected to result in decreased thickness, increased surface area but constant total volume of alveolar walls. Unfortunately, MASSARO and MASSARO [31] did not analyse volume or arithmetic mean thickness of alveolar wall tissue in response to the instillation of elastase.

Although the importance of elastolytic proteinases for the formation of emphysema has been highlighted by the initial findings of the destructive effects of elastases in this model, it is only of limited value to study the pathogenetic mechanisms involved in the development of the disease. Conversely, this model appears to be ideal for testing new therapeutic approaches to enhance alveolar regeneration within a reasonable amount of time (as compared with cigarette smoke exposure models (discussed further later)). Animals can be used for therapeutic studies $\sim 3$ weeks after the initial injury (see the Regeneration of alveoli section).

\section{GENETIC MODELS OF EMPHYSEMA}

Although exposure to noxious environmental agents, such as cigarette smoke, is a major risk factor for the development of COPD, several lines of evidence strongly suggest that susceptibility to developing the disease also depends on genetic factors [33]. Accumulating evidence from both human studies 
$[34,35]$ and comparative studies of various mouse strains [36] supports the notion that there is a heritability component of pulmonary function. Genome-wide linkage analysis in mice has identified genetic loci that comprise candidate genes, which are closely related to processes involved in morphogenesis and maintenance of lung structure [36, 37]. Notably, recent studies reported significant differences in lung structural characteristics between mouse strains [38-40]. This suggests that susceptibility to developing structural defects might also exhibit a component of heritability.

The importance of genes for the development of emphysema is highlighted by the finding that several naturally occurring mutant mouse strains have been reported to exhibit features of pulmonary emphysema, as has been comprehensively reviewed [4-6]. However, the mutants "tight-skin", "beige" and "blotchy", which have defects in genes that exhibit features of Marfan's syndrome (tight-skin with duplication of fibrillin 1 gene), Chediak-Higashi syndrome (beige with deletion in Lyst gene) and Menke's disease (blotchy with defect in the Menke gene) in humans, are characterised by multiple effects in several organ systems. With the exception of the mutant mouse strain "pallid", which was reported to have low levels of serum $\alpha_{1}$-AT associated with a severe deficiency in serum elastase inhibitory capacity [41], the relevance of these mutant strains for the pathogenesis of human lung emphysema is uncertain. To the best of the author's knowledge, no attempt has been made to demonstrate emphysema in these strains using a stereological approach.

With the establishment of transgenic mouse technologies, a number of candidate genes thought to be involved in the pathogenesis of COPD and emphysema have been studied by generating mice that are either deficient in or overexpress the gene of interest, as has been comprehensively reviewed [8, 4244]. When studying mutants or transgenic animals, the analysis of the time course of the formation of an emphysema-like phenotype is of major importance to distinguish developmental defects [45] that result in the impairment of alveolarisation, from the loss of (already formed) mature alveoli, which is characteristic of human pulmonary emphysema [44].

Alveolarisation, the formation of mature alveoli from primary sacculi, is achieved by secondary septa sprouting into the saccular airspaces, thus subdividing a sacculus into several alveoli [46]. In humans, rats and mice, a sudden and extensive formation of alveoli, which has been termed "bulk alveolarisation", is observed during early post-natal life. In humans, it starts at about foetal week 36 and continues until a post-natal age of $\sim 1-2$ yrs. In rats and mice, bulk alveolarisation begins at about day 4 after birth and is completed by post-natal day 14 . Formation of alveoli appears to continue at a slower rate until the final lung volume is achieved [47]. Therefore, only genetically modified animals that exhibit normal post-natal alveolarisation followed by a secondary loss of mature alveoli can be considered as valid models of human lung emphysema.

The distinction between developmental defects and the loss of mature alveoli is not possible using conventional transgenic animals, in which the gene of interest is either active or deficient during all stages of lung development. This can be achieved by using conditional transgenic animals [48]. In the tetracycline (tet)-inducible system, mice carrying the transgene of interest under control of the tet-operator (tetO) are bred with transgenic mice carrying the reverse tetracycline response transactivator (rtTA) under the control of a cell/tissue-specific promoter. Transgene expression is induced only in bitransgenic mice after treatment with doxycycline, which enables rtTA to bind to tetO elements and activate transcription. In such an approach, a cell-specific promoter (driving rtTA expression) is combined with the timing of doxycycline administration or withdrawal, and permits the transgene to be switched either "on" or "off" in subsets of cells (e.g. alveolar type II epithelial cells or bronchiolar Clara cells) at a given time-point during development or post-natal life [49]. A variation of this approach is conditional gene deletion using the loxP/cre-recombinase system, which allows temporal and/ or cell-specific silencing of the targeted gene. This approach facilitates the study of genetic loci, which, when disrupted, produce embryonic lethality [43]. However, the potentially adverse effects of rtTA or cre-recombinase expression alone and the need to study all the appropriate genetic (and doxycycline) controls have been highlighted recently [50, 51].

Numerous studies are published each year that claim a specific transgenic mouse strain demonstrates development of spontaneous emphysema or is characterised by increased or decreased susceptibility to develop emphysema upon cigarette smoke inhalation. Unfortunately, most of these studies report only measurements of MLI or MLC, on the basis of which the development of emphysema cannot be concluded convincingly, as previously outlined. Only a few studies used stereological approaches to clearly demonstrate that a loss of alveolar walls is present in transgenic mice [25, 52, 53]. For example, OcHs et al. [25] and JuNG et al. [53] used the whole armamentarium of design-based stereological tools to demonstrate that 12-week-old mice, which were deficient in surfactant protein (SP)-D or granulocyte-macrophage colonystimulating factor, or both, had significantly reduced alveolar surface area, alveolar number and increased number-weighted mean alveolar volume in comparison with age-matched wildtype mice. As qualitative $[54,55]$ and quantitative stereological studies (C. Klisch and H. Fehrenbach, both Clinical Research Group "Chronic Airway Diseases", Dept of Internal Medicine (Respiratory Medicine), Philipps-University of Marburg, Marburg, Germany; personal communication) revealed that alveolarisation was normal in SP-D-deficient mice, this transgenic mouse strain can indeed be considered as a model of human emphysema. The deficiency in SP-D was shown to be associated, for example, with a three-fold increase in the number and number-weighted mean volume of alveolar macrophages [25], and increased activity of matrix metalloproteinase (MMP)-9 and -12 from alveolar macrophage conditioned medium, whereas enzymatic activity in bronchoalveolar lavage fluid and mRNA expression of MMP-2 and -9 were similar to wild-type mice [54]. As hydrogen peroxide production of alveolar macrophage was increased by $\sim 10$-fold in mice deficient of SP-D, translocation of transcription factor nuclear factor (NF)- $\mathrm{BB}$ into the nucleus was increased, and nuclear extracts exhibited increased NF- $\mathrm{BB}$-binding activity in gel shift assays, MMP production appears to be enhanced via the reactive oxidant's species-sensitive NF- $\kappa B$ pathway in alveolar macrophages [55]. In contrast to these findings, in 
SP-D-deficient mice, recombinant rat SP-D was shown to selectively induce MMP-1, -3 and -12 in alveolar macrophages but not in peripheral blood monocytes of human smokers or human fibroblasts in vitro. This suggests that either SP-D has a similar effect on tissue inhibitors of MMPs (TIMP), which are important to counterbalance the effects of MMPs [56], or that SP-D deficiency indirectly augments MMP expression via aberrant surfactant turnover and the elaboration of proinflammatory cytokines [57]. As nothing is known about the expression and activity of TIMPs in SP-D-deficient mice, however, it is still unclear how these effects are regulated by $\mathrm{SP}-\mathrm{D}$ in vivo.

\section{INHALATION MODELS OF EMPHYSEMA}

Cigarette smoking is by far the most common cause of COPD in Westernised countries, accounting for $\sim 95 \%$ of cases [58], and it is a major risk factor for the development of lung cancer [59]. Hence, cigarette smoke exposure of experimental animals has been an attractive approach to studying carcinogenesis, as well as the pathogenetic pathways leading to one or more of the three pathological aspects of COPD seen in humans, i.e. mucus plugging, chronic obstructive bronchiolitis and emphysema [60].

With the single exception of the A/J mouse strain [61, 62], chronic exposure to cigarette smoke failed to increase the incidence of malignant tumours in the respiratory tract in mice, rats, hamsters, dogs and nonhuman primates as reviewed by CogGINS $[63,64]$. Despite considerable variation in the specific pulmonary responses to acute or chronic cigarette smoke exposure $[7,8,65,66]$, there is no doubt that cigarette smoke adversely affects the lungs of laboratory animals in various ways, including the induction of airway wall inflammation and epithelial cell alterations, like goblet cell metaplasia. Formation of emphysema as an effect of chronic cigarette smoke exposure, however, has conclusively been demonstrated by surprisingly few studies (table 1).

There are various reasons for the high degree of variability in the response to acute or chronic cigarette smoke exposure. First, cigarette smoke is a highly complex mixture of solid/liquid droplets (particulate phase) in a gaseous phase [71]. There are marked differences between main-stream smoke (the smoke that emerges from the mouth end of the cigarette during puffing), side-stream smoke (the smoke that emerges from the lit end of the cigarette between puffs) and environmental tobacco smoke (the mixture of side-stream smoke and exhaled main-stream smoke diluted in ambient air, the physical and chemical properties of which considerably change with time (ageing effects)). Therefore, even in acute exposure experiments, comprehensively reviewed recently [65], the choice of smoke used for exposure, as well as the specific mode of exposure, such as nose-only or whole-body exposure, are important factors modulating the lungs' response. This is also true for, for example, the brand and number of cigarettes, exposure time, time between exposure and measurement, species, strain, sex and age of the animals exposed.

Secondly, as the induction of emphysematous lesions by cigarette smoke requires exposure times of at least several months, it must be taken into account that significant interferences with age-dependent changes in lung morphology may occur and a valid interpretation of the data obtained may be very difficult. A number of studies reported the development of airspace enlargement, judged from MLI or MLC measurements, as an effect of chronic exposure to cigarette smoke. As mentioned previously, however, such data provide insubstantial evidence to conclude that emphysema had developed. This has been highlighted recently in a stereological study [32] of the effects of inhaled nitrogen dioxide $\left(\mathrm{NO}_{2}\right)$, an important gaseous component of cigarette smoke [72], which clearly demonstrated that airspace enlargement in rat lungs exposed to $\mathrm{NO}_{2}$ can be associated with accelerated lung growth instead of loss of alveolar septal walls. In the study by FEHRENBACH et al. [32], as in most studies performed in the field of emphysema research, animals were 8-10 weeks of age at the beginning of exposure, i.e. they were juvenile not adult individuals. After completion of bulk alveolarisation (by $\sim 3$ weeks of age in rats and mice), the lung continues to grow until adulthood ( $~ 5-6$ months of age in rats and mice) [22, 46, 73]. This is accompanied by a considerable increase in most of the structural parameters, such as total alveolar surface area, total alveolar wall volume or total capillary length [22]. Recent data indicate that alveoli, too, are continuously formed until the lung reaches its final volume $[47,74]$. Age-related changes in airspace size are also well documented in humans [23], as are age-related changes in lung function [75]. Both agedependent decline in lung function and increase in airspace size are significantly accelerated in smokers [12, 76]. As chronic inhalation experiments require a total exposure time of several weeks to months, as with cigarette smoke exposure for example, appropriate age-matched and follow-up groups should be implemented in such studies to be able to distinguish a loss of (already existing) alveolar walls and accompanying airspace enlargement from any effect caused by the inhibition or acceleration of lung growth and ageing. Despite some intriguing similarities, lung changes that evolve with age should be clearly distinguished from changes related to the development of a disease like COPD or emphysema, as was emphasised recently [77].

Only a few studies are available that demonstrate a decrease in total alveolar surface area and/or total alveolar septal tissue as a consequence of chronic exposure to cigarette smoke (table 1). Interpretations based on relative parameters, such as surface area per unit volume, and volume of airspace or septal tissue per unit volume of lung or parenchyma, are quite meaningless, as differences between groups may rely on changes in the nominator or denominator, or both (further discussed in the article by NYENGAARD and GUNDERSEN [78] in the present issue of the European Respiratory Review (ERR)). For example, although FORONJY et al. [79] observed changes in relative structural parameters, they did not find any changes in lung compliance, extracellular matrix and apoptosis in $\mathrm{A} / \mathrm{J}$ mice exposed to cigarette smoke for 6 months. This may simply reflect that the parameters chosen are not suitable to detect emphysema, rather than that these results suggest the mechanisms involved in anatomic emphysema are distinct from those that cause the loss of elastic recoil.

Long-term inhalation exposure to cigarette smoke is often associated with a loss of body weight [80]. As starvation (calorie restriction) alone results in an emphysema-like appearance of the lung [81], which is completely restored after 


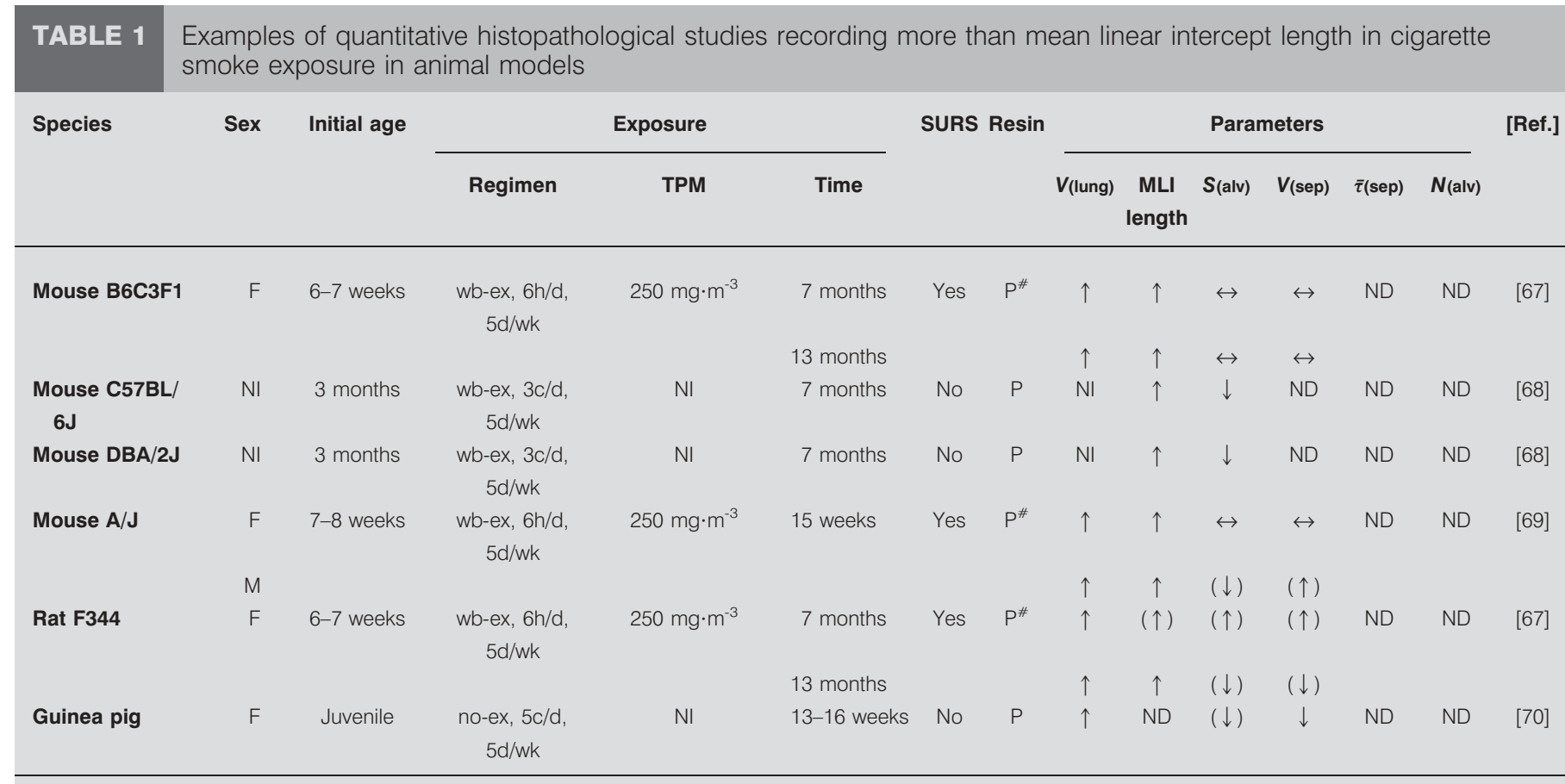

TPM: total particulate matter; SURS: systematic uniformly random sample; V(lung): fixed lung volume; MLI: mean linear intercept; $S$ (alv): total alveolar surface area; V(sep): total alveolar septal tissue volume; $\bar{\tau}(\mathrm{sep})$ : arithmetic mean thickness of alveolar septum; $N$ (alv): total number of alveoli; F: female; M: male; NI: no information given; h/d: hours per day; d/wk: days per week; c/d: cigarettes per day; wb-ex: whole-body exposure; no-ex: nose-only exposure; P: paraffin; ND: not done. $\uparrow:$ increase; $\downarrow$ : decrease; $\leftrightarrow$ : unchanged; parentheses indicate differences that do not reach the level of significance. ${ }^{\#}$ : data corrected for shrinkage.

refeeding [82], weight loss in long-term inhalation exposures may alone result in emphysematous changes of lung parenchyma. Appropriate calorie-restricted control groups may be necessary to distinguish effects caused by inhalation alone from those effects that may ensue as a result of reduced food consumption.

\section{INDUCTION OF APOPTOSIS TO MODEL EMPHYSEMA}

In their pioneering study, KASAHARA et al. [83] have demonstrated that the experimental induction of apoptosis in pulmonary endothelial cells by blockade of vascular endothelial growth factor receptor 2 results in enlargement of distal airspaces, as judged from measurements of MLI, thus opening up a new perspective of thinking about the pathogenetic mechanisms of emphysema [84-88]. While the concept of the proteaseantiprotease hypothesis relies on inflammation being the primary event, which leads to the destruction of extracellular matrix and subsequent loss of alveolar walls, KASAHARA et al. [83] highlighted the possibility that destruction of alveolar walls can occur in the absence of inflammation. Additional indication for the importance of apoptosis in the pathogenesis of emphysema came from several human studies, which demonstrated increased levels of apoptotic alveolar septal cells in emphysema patients [89-91]. To date, several groups have shown that induction of endothelial or alveolar epithelial cell apoptosis also results in an increase in MLI or in the mean diameter of alveolar profiles [92-94], with both being highly biased parameters (discussed further later). The effect of cigarette smoke exposure in inducing alveolar septal cell apoptosis was controversially discussed [95-97]. Unfortunately, none of these studies applied an unbiased method to quantify emphysema [83-97].
Recently, the present author's group has shown that exposure of juvenile rats to $\mathrm{NO}_{2}$ resulted in an eight-fold increase of alveolar septal cell apoptosis at day 3 , which was associated with a 14-fold increase in proliferation compared with agematched controls [32]. Although a $20 \%$ increase in MLC was evident by day 7, this was not accompanied by a loss of alveolar wall tissue. In contrast, exposure to $\mathrm{NO}_{2}$ resulted in an increase in total surface area and absolute volume of alveolar walls, indicating that normal lung growth was accelerated. These findings clearly demonstrate that analysis of airspace enlargement is insufficient to draw any firm conclusion on the presence or absence of emphysema. The study further indicates that an increase in apoptosis is difficult to interpret per se and that proliferation as the other factor affecting the balance of tissue homeostasis has to be analysed in parallel. Notably, an increase in both proliferation and apoptosis was observed in emphysema patients, indicating that cell turnover is accelerated and may be out of balance [89, 90, 98].

\section{REGENERATION OF ALVEOLI}

To date, there is no curative therapy available that can restore functional lung parenchyma that has been lost in an emphysematous human lung. However, experimental studies suggest that lost alveolar septal walls may be regenerated, e.g. in starvation- or elastase-induced emphysematous rodent lungs, by refeeding [99] or by treatment with all-trans-retinoic acid [31], respectively. In their recent review, MASSARO and MASSARO [100] emphasise that pulmonary alveoli can no longer be considered as incapable of regeneration and that fundamental programmes of alveolar turnover (loss and regeneration) are conserved from rodents to humans, which appears to 
provide the basis for new therapeutic approaches to treating emphysema.

As with the demonstration of a loss of alveolar structures in animal models of emphysema, the demonstration of alveolar regeneration can only be conclusive if appropriate parameters are chosen, such as total alveolar septal tissue volume, total alveolar surface area, or the number of alveoli per lung. Mere demonstration of the restoration of airspace size indices, such as MLI or MLC, which are critical parameters as previously discussed in the present article and by others [15, 18], is largely meaningless.

Taking into account the high interest of patients, researchers and the pharmaceutical industry in the development of new emphysema therapies, the question must be asked: is there really good evidence to support the notion that alveoli can be regenerated to restore a normal gas exchange area from an emphysematous lung? MASSARO and MASSARO [100] refer to several studies suggesting that alveoli can be regenerated from elastase- or cigarette smoke-induced emphysematous rat and mouse lung. Focusing on the morphological aspects of the studies referred to by MASSARO and MASSARO [100], however, the findings are only indicative, and not conclusive, of a therapeutic effect. Regeneration of alveoli in elastase-induced emphysema by systemic treatment of mice with all-transretinoic acid [101, 102], adrenomedullin [103], granulocytecolony stimulating factor [101], or of rats with hepatocyte growth factor [104] was inferred from the mere measurement of MLI, from alveolar area and density, or from radial alveolar counts, all highly bias-prone parameters. To date, systemic application of all-trans-retinoic acid is the only therapeutic intervention that has been demonstrated by means of unbiased stereological tools to reverse some of the effects of elastaseinduced emphysema in rats [31]. However, subsequent studies from other laboratories failed to reproduce these findings in rat [105], mouse [69, 106, 107] and rabbit [108]. No effect of alltrans-retinoic acid was seen in guinea pigs exposed to smoke [70]. Two of the studies carried out in rats and mice were performed by means of stereology $[69,105]$. The reasons for the discrepancies are still unclear.

There is good evidence to conclude that all-trans-retinoic acid is able to reinitiate the formation of alveoli in rat and mouse lungs treated with dexamethasone [109-111]. However, dexamethasone inhibits alveolar septation and induces premature microvascular maturation when administered during the period of post-natal alveologenesis [112, 113], thus being a model of a developmental defect rather than of emphysema. The beneficial effect of all-trans-retinoic acid in this model, which is characterised by an inherent capacity of the lung to resolve the defects after termination of (early) treatment [114, 115], should be clearly distinguished from any potential effect to regenerate alveoli in models of emphysema where a loss of (already existing) mature alveoli has to be compensated for.

\section{STEREOLOGICAL DESIGN FOR THE QUANTIFICATION OF EMPHYSEMA}

Most of the following subjects discussed in this article are addressed in more detail in the paper by NYENGAARD and GUNDERSEN [78] in the present issue of the ERR, as well as in two recent excellent reviews on the application of stereology to the study of lungs $[15,116]$. Therefore, only some selected aspects, which are of particular interest for emphysema research, are highlighted in the following sections.

\section{Fixation}

The size of the airspaces [20,21], as well as the alveolar surface area $[117,118]$, critically depends on the mode of fixation and the degree of inflation of the lung. Therefore, it is important to assure that the lungs to be studied are fixed at a well-defined state of inflation using a standardised protocol. Fixation by intratracheal instillation of fixative (preferably glutardialdehyde-based) at a constant pressure of $20-25-\mathrm{cm}$ fluid column is the method of choice in most settings, although fixation by pressure-controlled vascular perfusion at a defined state of inflation of the airspaces will preserve lung parenchymal architecture in a more physiological state $[117,118]$. Instillation is easily performed and results in quick and uniformly good preservation of lung tissues [119], whereas vascular perfusion requires more experience, time and equipment, and is more prone to alterations in structural characteristics due to deviations in the specific settings [120, 121]. Detailed protocols for fixation have been given elsewhere $[122,123]$.

As reduced elastic recoil in emphysematous lungs may result in overexpansion of the lung [31] and as alveolar epithelial surface area may be affected by the degree of inflation [117, 118], fixation by airway instillation at a given pressure might affect measurements of total alveolar surface area in emphysematous as compared with control lungs. As overexpansion can be expected to result in a stretch-related decrease in the thickness of the alveolar wall tissue, estimation of the mean arithmetic thickness and of the total volume of alveolar wall tissue will help to evaluate whether or not overexpansion has to be taken into account [32]. Volume-controlled procedures of lung fixation may help to resolve such problems [124-126] but, to best of the present author's knowledge, have not yet been used in quantitative morphological studies of experimental emphysema.

\section{Tissue sampling}

Lung function analysis reveals important additional parameters for the assessment of emphysema, e.g. forced expiratory volume in one second (FEV1; FEV0.1 in rodents), lung compliance and diffusing capacity of the lung for carbon monoxide, which are impaired in emphysematous lungs [12, 127]. Such parameters result from integrative measurements comprising the entirety of airspaces. In order to obtain corresponding integrative measurements of lung structures, it is of paramount importance that the tissue samples to be analysed are representative of the whole organ. This is even more important in experimental emphysema, as the characteristic lesions are heterogeneously distributed [128]. Therefore, the sampling design has to assure the following. 1) The reference volume, i.e. the volume of the fixed lung, must be determined (either by fluid displacement [129] or by the Cavalieri method [130]). 2) Each and every part of the lung must have the same chance of being analysed, which can be achieved by a systematic uniformly random sample (SURS) design. When applied at every single step of the analysis, SURS will ensure that the parameters recorded are representative of the lung as a whole, irrespective of the homogeneity or 
heterogeneity of the distribution of emphysematous lesions. The distribution of lesions within in the lung must by no means be "uniform" or "random"; heterogeneity within the lung will only affect the coefficients of variation of the parameters analysed. A detailed protocol of SURS has been described elsewhere [123].

\section{Parameters suggested for the analysis of emphysema}

As previously emphasised, quantitative demonstration of emphysema has to comprise both airspace enlargement and loss of the alveolar walls.

\section{Airspace enlargement}

The disadvantages of using MLI or MLC as an index for the assessment of airspace enlargement have already been discussed in the present article and have been reviewed in detail elsewhere [15, 18]. Another method that has recently been suggested as a more reliable alternative parameter to MLI [131], provoked a vivid and fundamental debate in the Journal of Applied Physiology about the problems related to the measurement of three-dimensional parameters on two-dimensional sections [132]. The most important point raised by stereologists in the field relates to the fact that measurements of the size of alveoli sampled with a single two-dimensional section will always be biased towards larger alveoli, as the chance of being hit by one cut is greater for larger than for smaller alveoli. Therefore, two-dimensional measurements, e.g. of the mean diameter of a population of alveolar profiles, the mean alveolar profile area or radial alveolar counts, are highly biased towards larger alveoli. As the size of an alveolus is a threedimensional characteristic, a proper approach to assess airspace enlargement would be to estimate the average volume of a representative sample of alveoli, i.e. the number-weighted mean alveolar volume $(\bar{v} N)$. This can be performed, for example, by sampling alveoli (according to number) by means of a selector (from exhaustive serial sections) and using the point-sampled intercepts method (further discussed later) for estimation of the mean alveolar volume, which is numberweighted as alveoli were chosen according to number [133, 134]. Alternatively, if alveolar numbers are determined using a physical disector approach (using two sections with known distance), $\bar{v} N$ can be indirectly determined from the total alveolar volume in cubic micrometres (using standard point counting and knowing the total lung volume) divided by the total number of alveoli per lung, as described recently $[135,136]$.

An interesting alternative to $\bar{v} N$ is the volume-weighted mean volume $(\bar{v} V)$, which is estimated by means of the point-sampled intercept method applied to single sections [137, 138]. This approach is less time-consuming but more difficult to interpret, as $\bar{v} V$ is the sum of $\bar{v} N$ and its variation. Hence, the "true" size of the average alveolus cannot be inferred from $\bar{v} V$. However, an increased heterogeneity in alveolar size, as is typical for emphysematous lungs, will result in an increase in $\bar{v} V$, whereas no change in $\bar{v} N$ may be seen, because emphysematous lesions are often surrounded by many small alveoli [131]. Hence, this sensitivity to variations in size suggests $\bar{v} V$ to be a helpful additional parameter with which to assess airspace enlargement in emphysema.
Loss of alveoli and alveolar walls

Alveoli are composed of the alveolar airspace and the surrounding alveolar walls. As each alveolus has an opening towards the alveolar duct lumen and the alveolar wall typically separates adjacent alveoli, thus contributing to more than one alveolus, alveoli are not discrete objects. Nevertheless, as for each three-dimensional structure, several fundamental global parameters can be recorded, i.e. total volume and total surface area of the alveolar walls, and the total number of alveoli (fig. 1). These parameters can be easily obtained by classical point and intersection counting and disector counts from thin sections of SUR samples, preferably embedded into glycolmethacrylate or epoxide resin to reduce shrinkage [139, 140]. Using a multilevel or cascade design at different magnifications $[15,116,141]$, the total volume of alveolar wall tissue from mouse or rat lung is estimated at high magnification levels (typically using a 40-60× lens) to determine the fraction of parenchyma occupied by alveolar wall tissue (volume density $V V($ awt,par)) by counting all test points hitting alveolar wall tissue $(P(a w t))$ and the points hitting all parenchymal compartments $(P($ par $))$ and calculating:

$$
V V(\text { awt }, \text { par })=P(\text { awt }) / P(\text { par })\left(\mathrm{mm}^{3} \cdot \mathrm{mm}^{-3}\right)
$$

At lower-level magnification (typically using a $10 \times$ lens), the fraction of lung occupied by parenchyma $(V V$ (par,lung)) is estimated by counting all points hitting parenchymal structures $(P($ par $))$ relative to all points falling on lung structures (P(lung)) and calculating:

$$
V V(\text { par,lung })=P(\text { par }) / P(\text { lung })\left(\mathrm{mm}^{3} \cdot \mathrm{mm}^{-3}\right)
$$

Knowing the reference volume, i.e. the volume of the fixed lung (V(lung)) in $\mathrm{mm}^{3}$, from independent measurements (as previously discussed), the total volume of alveolar wall tissue $(V(a w t))$ is calculated by the simple formula:

$$
V(\text { awt })=V V(\text { awt,par }) \times V V(\text { par,lung }) \times V(\text { lung })\left(\mathrm{mm}^{3}\right)
$$

Similarly, total alveolar surface area is obtained by estimating the density of alveolar wall surface area per parenchymal volume $(S V$ (aw,par) $)$ at high magnification using a test system with line segments of a calibrated length per test point $(L P)$, and counting the sum of intersections of the line segments with the alveolar walls $(I(\mathrm{aw}))$ as well as the sum of $(P(\mathrm{par}))$ to calculate:

$$
S_{V(\text { aw }, \text { par })}=(2 \times I(\text { aw })) /(P(\text { par }) \times L P)\left(\mathrm{mm}^{-1}\right)
$$

Total alveolar surface area $(S(\mathrm{aw}))$ can then be obtained according to the following formula:

$$
S_{(\text {aw })}=S_{V(\text { aw, par })} \times V V(\text { par,lung }) \times V(\text { lung })\left(\mathrm{mm}^{2}\right)
$$

The arithmetic mean thickness of the alveolar wall tissue ( $\bar{\tau}$ aw) can be calculated from these point and intersection counts according to the following formula:

$$
\bar{\tau}_{\mathrm{aw}}=L P \times P(\mathrm{awt}) /(2 \times I(\mathrm{aw}))(\mu \mathrm{m})
$$

The most challenging task is to estimate the number of alveoli per lung. This can be performed by means of a selector approach (using exhaustive serial sections) [133, 134] or, much 

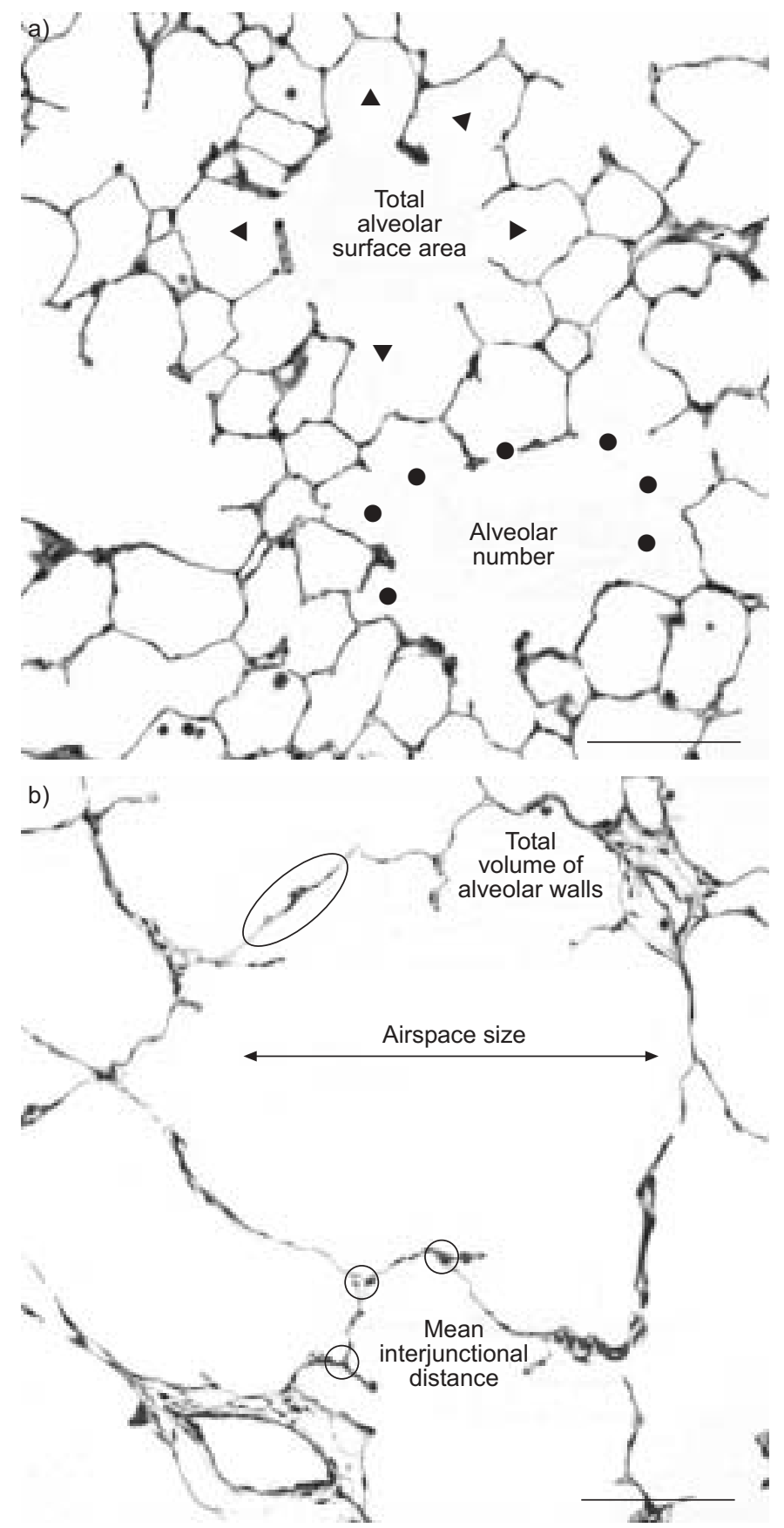

FIGURE 1. Gas exchange region of rat lungs fixed by intratracheal instillation of fixative at a pressure of $20-\mathrm{cm}$ fluid column at day 25 after intratracheal instillation of a) diluent or b) porcine pancreatic elastase. Parameters relevant for the assessment of emphysema are indicated. For analysis of alveolar number by means of the physical disector approach, pairs of sections with known distance are required. Scale bars $=150 \mu \mathrm{m}$.

more efficiently, by a physical disector approach (using two sections with known distance), as described in detail recently $[135,136]$. The use of the physical disector in conjunction with the fractionator (NYENGAARD and GUNDERSEN [78] in the present issue of the ERR)), elegantly avoids any problem related to shrinkage [136]. As previously mentioned, alveoli are not discrete objects but are connected to each other via alveolar openings into the alveolar ducts. Therefore, the connectivity of the alveoli has to be determined (for details, see [142]), which in practice means that the alveolar opening rings are counted to obtain an estimate of alveolar number $[135,136]$. This, however, may be difficult in emphysematous lungs because portions of the alveolar opening rings may be destroyed along with the alveolar walls. To overcome this problem and to reduce the amount of time for analysis, a new parameter has been suggested (D.M. Hyde, California National Primate Research Center, University of California, Davis, CA, USA; personal communication): the mean alveolar face length, which is the mean distance from one interalveolar wall junction to the adjacent junction. The mean alveolar face length appears to be highly correlated with alveolar number, while also being independent of the degree of inflation. All these parameters can be estimated, for example, using the recently developed ALP-sector as a multipurpose coherent test system, with test area (A), test lines (L) and test points (P), which allows the assessement of volume, surface and length densities per unit volume from point hits $(P)$, intersection counts $(I)$, and transect counts $(Q)$, whereby the reference area is estimated by the number of test points included in the section profile [15].

\section{CONCLUSIONS}

To date, a variety of animal models have been suggested as models of pulmonary emphysema. Recognising that on the basis of the widely accepted definition of pulmonary emphysema as the "abnormal permanent enlargement of the airspaces distal to the terminal bronchioles, accompanied by destruction of their walls" [10], quantitative morphology is the only method by which to reliably assess the presence of emphysema. Careful inspection of many of the proposed animal models reveals that both criteria of emphysema definition were demonstrated in surprisingly few of them. Stereology offers the appropriate tools to quantify the relevant parameters and continues to develop additional tools that will help to assess the reliability of any new model proposed. If use of inappropriate parameters continues for the evaluation of existing animal models of emphysema, thinking and resources are likely to be misdirected. Unless the poor methods widely used in the quantification of experimental emphysema are improved, the proposed models will limit understanding and treatment of human emphysema.

\section{REFERENCES}

1 Hogg JC. Pathophysiology of airflow limitation in chronic obstructive pulmonary disease. Lancet 2004; 364: 709-721.

2 Shapiro SD, Ingenito EP. The pathogenesis of chronic obstructive pulmonary disease: advances in the past 100 years. Am J Respir Cell Mol Biol 2005; 32: 367-372.

3 Barnes PJ, Stockley RA. COPD: current therapeutic interventions and future approaches. Eur Respir J 2005; 25: 1084-1106.

4 Shapiro SD. Animal models for COPD. Chest 2000; 117: 223S-227S.

5 Mahadeva R, Shapiro SD. Chronic obstructive pulmonary disease 3: experimental animal models of pulmonary emphysema. Thorax 2002; 57: 908-914. 
6 Snider GL, Martorana PA, Lucey EC, Lungarella G. Animal models of emphysema. In: Voelkel NF, MacNee W, eds. Chronic Obstructive Lung Diseases. Hamilton, BC Decker, 2002; pp. 237-256.

7 Wright JL, Churg A. Animal models of cigarette smokeinduced COPD. Chest 2002; 122: 301S-306S.

8 Brusselle GG, Bracke KR, Maes T, et al. Murine models of COPD. Pulm Pharmacol Ther 2006; 19: 155-165.

9 Vlahos R, Bozinovski S, Gualano RC, Ernst M, Anderson GP. Modelling COPD in mice. Pulm Pharmacol Ther 2006; 19: 12-17.

10 American Thoracic Society. Standards for the diagnosis and care of patients with chronic obstructive pulmonary disease. Am J Respir Crit Care Med 1995; 152: S77-S121.

11 Thurlbeck WM. Internal surface area and other measurements in emphysema. Thorax 1967; 22: 483-496.

12 Hogg JC, Wright JL, Wiggs BR, Coxson HO, Opazo SA, Pare PD. Lung structure and function in cigarette smokers. Thorax 1994; 49: 473-478.

13 Wiebe BM, Laursen H. Lung morphometry by unbiased methods in emphysema: bronchial and blood vessel volume, alveolar surface area and capillary length. APMIS 1998; 106: 651-656.

14 Fehrenbach $H$. Animal models of chronic obstructive pulmonary disease: some critical remarks. Pathobiology 2002; 70: 277-283.

15 Weibel ER, Hsia CC, Ochs M. How much is there really? Why stereology is essential in lung morphometry. J Appl Physiol 2007; 102: 459-467.

16 Escolar JD, Gallego B, Tejero C, Escolar MA. Changes occurring with increasing age in the rat lung: morphometrical study. Anat Rec 1994; 239: 287-296.

17 Campbell H, Tomkeieff SI. Calculation of the internal surface of a lung. Nature 1952; 170: 116-117.

18 Massaro GD, Massaro D. Formation of pulmonary alveoli and gas-exchange surface area: quantitation and regulation. Annu Rev Physiol 1996; 58: 73-92.

19 Ito S, Bartolak-Suki E, Shipley JM, Parameswaran H, Majumdar A, Suki B. Early emphysema in the tight skin and pallid mice: roles of microfibril-associated glycoproteins, collagen, and mechanical forces. Am J Respir Cell Mol Biol 2006; 34: 688-694.

20 Thurlbeck WM. Measurement of distal airspace size. Thorax 1994; 49: 625.

21 Soutiere SE, Mitzner W. On defining total lung capacity in the mouse. J Appl Physiol 2004; 96: 1658-1664.

22 Pinkerton KE, Green FHY. Normal aging of the lung. In: Harding R, Pinkerton KE, Plopper C, eds. The Lung Development, Aging and the Environment. London, Elsevier Academic Press, 2004; pp. 213-233.

23 Gillooly M, Lamb D. Airspace size in lungs of lifelong non-smokers: effect of age and sex. Thorax 1993; 48: 39-43.

24 Heemskerk-Gerritsen BA, Dijkman JH, ten HaveOpbroek AA. Stereological methods: a new approach in the assessment of pulmonary emphysema. Microsc Res Tech 1996; 34: 556-562.

25 Ochs M, Knudsen L, Allen L, et al. GM-CSF mediates alveolar epithelial type II cell changes but not emphysema-like pathology in SP-D deficient mice. Am J Physiol Lung Cell Mol Physiol 2004; 287: L1333-L1341.
26 Gross P, Pfitzer EA, Tolker E, Babyak MA, Kaschak M. Experimental emphysema: its production with papain in normal and silicotic rats. Arch Environ Health 1965; 11: 50-58.

27 Shapiro SD. The pathogenesis of emphysema: the elastase:antielastase hypothesis 30 years later. Proc Assoc Am Physicians 1995; 107: 346-352.

28 Kao RC, Wehner NG, Skubitz KM, Gray BH, Hoidal JR. Proteinase 3. A distinct human polymorphonuclear leukocyte proteinase that produces emphysema in hamsters. J Clin Invest 1988; 82: 1963-1973.

29 Hayes JA, Korthy A, Snider GL. The pathology of elastase-induced panacinar emphysema in hamsters. J Pathol 1975; 117: 1-14.

30 Busch RH, Lauhala KE, Loscutoff SM, McDonald KE. Experimental pulmonary emphysema induced in the rat by intratracheally administered elastase: morphogenesis. Environ Res 1984; 33: 497-513.

31 Massaro GD, Massaro D. Retinoic acid treatment abrogates elastase-induced pulmonary emphysema in rats. Nat Med 1997; 3: 675-677.

32 Fehrenbach H, Zimmermann G, Starke E, et al. Nitrogen dioxide induces apoptosis and proliferation but not emphysema in rat lungs. Thorax 2007; 62: 438-446.

33 Silverman EK. Progress in chronic obstructive pulmonary disease genetics. Proc Am Thorac Soc 2006; 3: 405-408.

34 Wilk JB, Djousse L, Arnett DK, et al. Evidence for major genes influencing pulmonary function in the NHLBI family heart study. Genet Epidemiol 2000; 19: 81-94.

35 Joost O, Wilk JB, Cupples LA, et al. Genetic loci influencing lung function: a genome-wide scan in the Framingham Study. Am J Respir Crit Care Med 2002; 165: 795-799.

36 Reinhard C, Meyer B, Fuchs H, et al. Genomewide linkage analysis identifies novel genetic Loci for lung function in mice. Am J Respir Crit Care Med 2005; 171: 880-888.

37 Ganguly K, Reinhard C, Bolle I, et al. Identification of genetic pathways regulating lung function in mice: single nucleotide polymorphisms (SNPs) detection approach. Proc Am Thorac Soc 2006; 3: A731.

38 Soutiere SE, Mitzner W. Comparison of postnatal lung growth and development between $\mathrm{C} 3 \mathrm{H} / \mathrm{HeJ}$ and C57BL/ 6J mice. J Appl Physiol 2006; 100: 1577-1583.

39 Fehrenbach H, Hühn T, Reinhard C, et al. Strain- and sexspecific differences in alveolar septal wall ultrastructure of inbred $\mathrm{C} 3 \mathrm{H} / \mathrm{HeJ}$ and JF1/Msf mice. Proc Am Thoracic Soc 2005; 2: A500.

40 Soutiere SE, Tankersley CG, Mitzner W. Differences in alveolar size in inbred mouse strains. Respir Physiol Neurobiol 2004; 140: 283-291.

41 Martorana PA, Brand T, Gardi C, et al. The pallid mouse. A model of genetic alpha 1-antitrypsin deficiency. Lab Invest 1993; 68: 233-241.

42 Elias JA, Kang MJ, Crouthers K, Homer R, Lee CG. State of the art. Mechanistic heterogeneity in chronic obstructive pulmonary disease: insights from transgenic mice. Proc Am Thorac Soc 2006; 3: 494-498.

43 Bridges JP, Weaver TE. Use of transgenic mice to study lung morphogenesis and function. Ilar J 2006; 47: 22-31. 
44 Shapiro SD. Transgenic and gene-targeted mice as models for chronic obstructive pulmonary disease. Eur Respir J 2007; 29: 375-378.

45 Roth-Kleiner M, Post M. Similarities and dissimilarities of branching and septation during lung development. Pediatr Pulmonol 2005; 40: 113-134.

46 Burri PH. Structural aspects of postnatal lung development - alveolar formation and growth. Biol Neonate 2006; 89: 313-322.

47 Hyde DM, Putney LF, Quesenberry N, Singh P, Tyler NK. Alveoli increase with lung volume into young adulthood in Rhesus monkeys. Proc Am Thorac Soc 2006; 3: A676.

48 Hokuto I, Perl AK, Whitsett JA. Prenatal, but not postnatal, inhibition of fibroblast growth factor receptor signaling causes emphysema. J Biol Chem 2003; 278: 415-421.

49 Perl AK, Tichelaar JW, Whitsett JA. Conditional gene expression in the respiratory epithelium of the mouse. Transgenic Res 2002; 11: 21-29.

50 Sisson TH, Hansen JM, Shah M, et al. Expression of the reverse tetracycline-transactivator gene causes emphysema-like changes in mice. Am J Respir Cell Mol Biol 2006; 34: 552-560.

51 Whitsett JA, Perl AK. Conditional control of gene expression in the respiratory epithelium: a cautionary note. Am J Respir Cell Mol Biol 2006; 34: 519-520.

52 Hawgood S, Ochs M, Jung A, et al. Sequential targeted deficiency of SP-A and -D leads to progressive alveolar lipoproteinosis and emphysema. Am J Physiol Lung Cell Mol Physiol 2002; 283: L1002-L1010.

53 Jung A, Allen L, Nyengaard JR, et al. Design-based stereological analysis of the lung parenchymal architecture and alveolar type II cells in surfactant protein A and D double deficient mice. Anat Rec A Discov Mol Cell Evol Biol 2005; 286: 885-890.

54 Wert SE, Yoshida M, LeVine AM, et al. Increased metalloproteinase activity, oxidant production, and emphysema in surfactant protein D gene-inactivated mice. Proc Natl Acad Sci USA 2000; 97: 5972-5977.

55 Yoshida M, Whitsett JA. Alveolar macrophages and emphysema in surfactant protein-D-deficient mice. Respirology 2006; 11: S37-S40.

56 Cawston T, Carrere S, Catterall J, et al. Matrix metalloproteinases and TIMPs: properties and implications for the treatment of chronic obstructive pulmonary disease. Novartis Found Symp 2001; 234: 205-218, discussion 218-228.

57 Crippes Trask B, Malone MJ, Lum EH, Welgus HG, Crouch EC, Shapiro SD. Induction of macrophage matrix metalloproteinase biosynthesis by surfactant protein D. J Biol Chem 2001; 276: 37846-37852.

58 Barnes PJ, Shapiro SD, Pauwels RA. Chronic obstructive pulmonary disease: molecular and cellular mechanisms. Eur Respir J 2003; 22: 672-688.

59 Massion PP, Carbone DP. The molecular basis of lung cancer: molecular abnormalities and therapeutic implications. Respir Res 2003; 4: 12.

60 Barnes PJ. Chronic obstructive pulmonary disease. N Engl J Med 2000; 343: 269-280.

61 Witschi H, Espiritu I, Dance ST, Miller MS. A mouse lung tumor model of tobacco smoke carcinogenesis. Toxicol Sci 2002; 68: 322-330.
62 Witschi H. A/J mouse as a model for lung tumorigenesis caused by tobacco smoke: strengths and weaknesses. Exp Lung Res 2005; 31: 3-18.

63 Coggins CR. A review of chronic inhalation studies with mainstream cigarette smoke in rats and mice. Toxicol Pathol 1998; 26: 307-314.

64 Coggins CR. A review of chronic inhalation studies with mainstream cigarette smoke, in hamsters, dogs, and nonhuman primates. Toxicol Pathol 2001; 29: 550-557.

65 Van der Vaart H, Postma DS, Timens W, ten Hacken NH. Acute effects of cigarette smoke on inflammation and oxidative stress: a review. Thorax 2004; 59: 713-721.

66 Nikula KJ, Green FH. Animal models of chronic bronchitis and their relevance to studies of particleinduced disease. Inhal Toxicol 2000; 12: Suppl. 4, 123-153.

67 March TH, Barr EB, Finch GL, et al. Cigarette smoke exposure produces more evidence of emphysema in B6C3F1 mice than in F344 rats. Toxicol Sci 1999; 51: 289-299.

68 Cavarra E, Bartalesi B, Lucattelli M, et al. Effects of cigarette smoke in mice with different levels of alpha(1)proteinase inhibitor and sensitivity to oxidants. Am J Respir Crit Care Med 2001; 164: 886-890.

69 March TH, Bowen LE, Finch GL, Nikula KJ, Wayne BJ, Hobbs $\mathrm{CH}$. Effects of strain and treatment with inhaled aII-trans-retinoic acid on cigarette smoke-induced pulmonary emphysema in mice. COPD 2005; 2: 289-302.

70 Meshi B, Vitalis TZ, Ionescu D, et al. Emphysematous lung destruction by cigarette smoke. The effects of latent adenoviral infection on the lung inflammatory response. Am J Respir Cell Mol Biol 2002; 26: 52-57.

71 Borgerding M, Klus H. Analysis of complex mixtures cigarette smoke. Exp Toxicol Pathol 2005; 57: 43-73.

72 Moschandreas DJ, Relwani SM, O'Neill HJ, Cole JT, Elkins RH, Macriss RA. Characterization of Emission Rates from Indoor Combustion Sources. GRI 85/0075. Chicago, Gas Research Institute, 1985.

73 Mizuuchi T, Kida K, Fujino Y. Morphological studies of growth and aging in the lungs of Fischer 344 male rats. Exp Gerontol 1994; 29: 553-567.

74 Schittny JC, Mund SI, Stampanoni M. Local capillary splitting permits (late) alveolarization of lungs after the maturation of the alveolar microvasculature. Proc Am Thorac Soc 2006; 3: A674.

75 Pauwels RA, Rabe KF. Burden and clinical features of chronic obstructive pulmonary disease (COPD). Lancet 2004; 364: 613-620.

76 Scanlon PD, Connett JE, Waller LA, Altose MD, Bailey WC, Buist AS. Smoking cessation and lung function in mild-to-moderate chronic obstructive pulmonary disease. The Lung Health Study. Am J Respir Crit Care Med 2000; 161: 381-390.

77 Teramoto S, Ishii M. Aging, the aging lung, and senile emphysema are different. Am J Respir Crit Care Med 2007; 175: 197.

78 Nyengaard JR, Gundersen HJG. Sampling for stereology in lungs. Eur Respir Rev 2006; 15: 107-114.

79 Foronjy RF, Mercer BA, Maxfield MW, Powell CA, D'Armiento J, Okada Y. Structural emphysema does not correlate with lung compliance: lessons from the mouse smoking model. Exp Lung Res 2005; 31: 547-562. 
80 Huber GL, Davies P, Zwilling GR, et al. A morphologic and physiologic bioassay for quantifying alterations in the lung following experimental chronic inhalation of tobacco smoke. Bull Eur Physiopathol Respir 1981; 17: 269-327.

81 Sahebjami H, Wirman JA. Emphysema-like changes in the lungs of starved rats. Am Rev Respir Dis 1981; 124: 619-624.

82 Massaro D, Massaro GD, Baras A, Hoffman EP, Clerch LB. Calorie-related rapid onset of alveolar loss, regeneration, and changes in mouse lung gene expression. Am J Physiol Lung Cell Mol Physiol 2004; 286: L896-L906.

83 Kasahara Y, Tuder RM, Taraseviciene-Stewart L, et al. Inhibition of VEGF receptors causes lung cell apoptosis and emphysema. J Clin Invest 2000; 106: 1311-1319.

84 Shapiro SD. Vascular atrophy and VEGFR-2 signaling: old theories of pulmonary emphysema meet new data. $J$ Clin Invest 2000; 106: 1309-1310.

85 Tuder RM, Petrache I, Elias JA, Voelkel NF, Henson PM. Apoptosis and emphysema: the missing link. Am J Respir Cell Mol Biol 2003; 28: 551-554.

86 Henson PM, Vandivier RW, Douglas IS. Cell death, remodeling, and repair in chronic obstructive pulmonary disease? Proc Am Thorac Soc 2006; 3: 713-717.

87 Demedts IK, Demoor T, Bracke KR, Joos GF, Brusselle GG. Role of apoptosis in the pathogenesis of COPD and pulmonary emphysema. Respir Res 2006; 7: 53.

88 Tuder RM, Yoshida T, Arap W, Pasqualini R, Petrache I. State of the art. Cellular and molecular mechanisms of alveolar destruction in emphysema: an evolutionary perspective. Proc Am Thorac Soc 2006; 3: 503-510.

89 Imai K, Mercer BA, Schulman LL, Sonett JR, $\mathrm{D}^{\prime}$ Armiento JM. Correlation of lung surface area to apoptosis and proliferation in human emphysema. Eur Respir J 2005; 25: 250-258.

90 Yokohori N, Aoshiba K, Nagai A. Increased levels of cell death and proliferation in alveolar wall cells in patients with pulmonary emphysema. Chest 2004; 125: 626-632.

91 Kasahara Y, Tuder RM, Cool CD, Lynch DA, Flores SC, Voelkel NF. Endothelial cell death and decreased expression of vascular endothelial growth factor and vascular endothelial growth factor receptor 2 in emphysema. Am J Respir Crit Care Med 2001; 163: 737-744.

92 Tang K, Rossiter HB, Wagner PD, Breen EC. Lungtargeted VEGF inactivation leads to an emphysema phenotype in mice. J Appl Physiol 2004; 97: 1559-1566.

93 Aoshiba K, Yokohori N, Nagai A. Alveolar wall apoptosis causes lung destruction and emphysematous changes. Am J Respir Cell Mol Biol 2003; 28: 555-562.

94 Petrache I, Natarajan V, Zhen L, et al. Ceramide upregulation causes pulmonary cell apoptosis and emphysema-like disease in mice. Nat Med 2005; 11: 491-498.

95 Ma B, Kang MJ, Lee CG, et al. Role of CCR5 in IFNgamma-induced and cigarette smoke-induced emphysema. J Clin Invest 2005; 115: 3460-3472.

96 Wickenden JA, Clarke MC, Rossi AG, et al. Cigarette smoke prevents apoptosis through inhibition of caspase activation and induces necrosis. Am J Respir Cell Mol Biol 2003; 29: 562-570.

97 Ma B, Kang MJ, Lee CG, et al. Role of CCR5 in IFNgamma-induced and cigarette smoke-induced emphysema. J Clin Invest 2005; 115: 3460-3472.
98 Calabrese F, Giacometti C, Beghe B, et al. Marked alveolar apoptosis/proliferation imbalance in end-stage emphysema. Respir Res 2005; 6: 14.

99 De Carlo Massaro G, Radaeva S, Clerch LB, Massaro D. Lung alveoli: endogenous programmed destruction and regeneration. Am J Physiol Lung Cell Mol Physiol 2002; 283: 305-309.

100 Massaro D, Massaro GD. Toward therapeutic pulmonary alveolar regeneration in humans. Proc Am Thorac Soc 2006; 3: 709-712.

101 Ishizawa K, Kubo H, Yamada $\mathrm{M}$, et al. Bone marrowderived cells contribute to lung regeneration after elastase-induced pulmonary emphysema. FEBS Lett 2004; 556: 249-252.

102 Belloni PN, Garvin L, Mao CP, Bailey-Healy I, Leaffer D. Effects of all-trans-retinoic acid in promoting alveolar repair. Chest 2000; 117: 235S-241S.

103 Murakami S, Nagaya N, Itoh T, et al. Adrenomedullin regenerates alveoli and vasculature in elastase-induced pulmonary emphysema in mice. Am J Respir Crit Care Med 2005; 172: 581-589.

104 Shigemura N, Sawa Y, Mizuno S, et al. Amelioration of pulmonary emphysema by in vivo gene transfection with hepatocyte growth factor in rats. Circulation 2005; 111: 1407-1414.

105 March TH, Cossey PY, Esparza DC, Dix KJ, McDonald JD, Bowen LE. Inhalation administration of all-trans-retinoic acid for treatment of elastase-induced pulmonary emphysema in Fischer 344 rats. Exp Lung Res 2004; 30: 383-404.

106 Lucey EC, Goldstein RH, Breuer R, Rexer BN, Ong DE, Snider GL. Retinoic acid does not affect alveolar septation in adult FVB mice with elastase-induced emphysema. Respiration 2003; 70: 200-205.

107 Fujita M, Ye Q, Ouchi H, et al. Retinoic acid fails to reverse emphysema in adult mouse models. Thorax 2004; 59: 224-230.

108 Nishi Y, Boswell V, Ansari T, Piprawala F, Satchi S, Page CP. Elastase-induced changes in lung function: relationship to morphometry and effect of drugs. Pulm Pharmacol Ther 2003; 16: 221-229.

109 Massaro GD, Massaro D. Retinoic acid treatment partially rescues failed septation in rats and in mice. Am J Physiol Lung Cell Mol Physiol 2000; 278: 955-960.

110 Maden M. Retinoids have differing efficacies on alveolar regeneration in a dexamethasone-treated mouse. Am J Respir Cell Mol Biol 2006; 35: 260-267.

111 Hind M, Maden M. Retinoic acid induces alveolar regeneration in the adult mouse lung. Eur Respir J 2004; 23: 20-27.

112 Tschanz SA, Damke BM, Burri PH. Influence of postnatally administered glucocorticoids on rat lung growth. Biol Neonate 1995; 68: 229-245.

113 Roth-Kleiner M, Berger TM, Tarek MR, Burri PH, Schittny JC. Neonatal dexamethasone induces premature microvascular maturation of the alveolar capillary network. Dev Dyn 2005; 233: 1261-1271.

114 Luyet C, Burri PH, Schittny JC. Suppression of cell proliferation and programmed cell death by dexamethasone during postnatal lung development. Am J Physiol Lung Cell Mol Physiol 2002; 282: 477-483. 
115 Schwyter M, Burri PH, Tschanz SA. Geometric properties of the lung parenchyma after postnatal glucocorticoid treatment in rats. Biol Neonate 2003; 83: 57-64.

116 Ochs M. A brief update on lung stereology. J Microsc 2006; 222: 188-200.

117 Gil J, Bachofen H, Gehr P, Weibel ER. Alveolar volumesurface area relation in air- and saline-filled lungs fixed by vascular perfusion. J Appl Physiol 1979; 47: 990-1001.

118 Tschumperlin DJ, Margulies SS. Alveolar epithelial surface area-volume relationship in isolated rat lungs. J Appl Physiol 1999; 86: 2026-2033.

119 Bur S, Bachofen H, Gehr P, Weibel ER. Lung fixation by airway instillation: effects on capillary hematocrit. Exp Lung Res 1985; 9: 57-66.

120 Bachofen H, Ammann A, Wangensteen D, Weibel ER. Perfusion fixation of lungs for structure-function analysis: credits and limitations. J Appl Physiol 1982; 53: 528-533.

121 Bachofen $H$, Schürch S, Urbinelli M, Weibel ER. Relations among alveolar surface tension, surface area, volume, and recoil pressure. J Appl Physiol 1987; 62: 1878-1887.

122 Gehr P, Crapo JD. Morphometric analysis of the gas exchange region of the lung. In: Gardner DE, Crapo JD, Massaro EJ, eds. Toxicology of the Lung. New York, Raven Press, 1988; pp. 1-41.

123 Fehrenbach $\mathrm{H}$, Ochs M. Studying lung ultrastructure. In: Uhlig S, Taylor AE, eds. Methods in Pulmonary Research. Basel, Birkhäuser Verlag, 1998; pp. 429-454.

124 Mittermayer C, Wybitul K, Rau WS, Ostendorf P, Riede UN. Standardized fixation of human lung for radiology and morphometry; Description of a "two chamber"'-system with formaldehyde vapor inflation. Pathol Res Pract 1978; 162: 115-130.

125 Turner CR, Zucek S, Knudsen DJ, Wheeldon EB. Microwave fixation of the lung. Stain Technol 1990; 65: 95-101.

126 Litzlbauer HD, Neuhaeuser CA, Moell A, et al. Threedimensional imaging and morphometic analysis of alveolar tissue from microfocal X- ray computed tomography. Am J Physiol Lung Cell Mol Physiol 2006; 291: 535-545.

127 Gugger M, Gould G, Sudlow MF, Wraith PK, MacNee W. Extent of pulmonary emphysema in man and its relation to the loss of elastic recoil. Clin Sci (Lond) 1991; 80: 353-358.

128 Ito S, Ingenito EP, Arold SP, et al. Tissue heterogeneity in the mouse lung: effects of elastase treatment. J Appl Physiol 2004; 97: 204-212.
129 Scherle W. A simple method for volumetry of organs in quantitative stereology. Mikroskopie 1970; 26: 57-60.

130 Yan X, Polo Carbayo JJ, Weibel ER, Hsia CC. Variation of lung volume after fixation when measured by immersion or Cavalieri method. Am J Physiol Lung Cell Mol Physiol 2003; 284: L242-L245.

131 Parameswaran $\mathrm{H}$, Majumdar A, Ito S, Alencar AM, Suki B. Quantitative characterization of airspace enlargement in emphysema. J Appl Physiol 2006; 100: 186-193.

132 Weibel ER, Parameswaran H, Majumdar A, et al. Morphological quantitation of emphysema: a debate. J Appl Physiol 2006; 100: 1419-1425.

133 Cruz-Orive LM. Particle number can be estimated using a disector of unknown thickness: the selector. I Microsc 1987; 145: 121-142.

134 Blanco LN, Massaro GD, Massaro D. Alveolar dimensions and number: developmental and hormonal regulation. Am J Physiol 1989; 257: L240-L247.

135 Ochs M, Nyengaard JR, Jung A, et al. The number of alveoli in the human lung. Am J Respir Crit Care Med 2004; 169: $120-124$.

136 Hyde DM, Tyler NK, Putney LF, Singh P, Gundersen HJ. Total number and mean size of alveoli in mammalian lung estimated using fractionator sampling and unbiased estimates of the Euler characteristic of alveolar openings. Anat Rec 2004; 277A: 216-226.

137 Gundersen HJ, Jensen EB. Stereological estimation of the volume-weighted mean volume of arbitrary particles observed on random sections. J Microsc 1985; 138: 127-142.

138 Fehrenbach A, Ochs M, Wittwer T, et al. Stereological estimation of the volume weighted mean volumes of alveoli and acinar pathways in the rat lung to characterise alterations after ischaemia/reperfusion. J Anat 1999; 194: 127-135.

139 Elias H, Hyde DM. An elementary introduction to stereology (quantitative microscopy). Am J Anat 1980; 159: 412-446.

140 Dorph-Petersen KA, Nyengaard JR, Gundersen HJ. Tissue shrinkage and unbiased stereological estimation of particle number and size. J Microsc 2001; 204: 232-246.

141 Cruz-Orive LM, Weibel ER. Sampling designs for stereology. J Microsc 1981; 122: 235-257.

142 Gundersen HJ, Boyce RW, Nyengaard JR, Odgaard A. The Conneulor: unbiased estimation of connectivity using physical disectors under projection. Bone 1993; 14: 217-222. 